\title{
Gazing into the crystal ball: Preventing the inevitable shortage of cardiothoracic surgeons
}

\author{
Tom C. Nguyen, MD
}

\footnotetext{
From the Department of Cardiothoracic and Vascular Surgery, University of Texas Medical School at Houston, Houston, Tex.

Disclosures: Author has nothing to disclose with regard to commercial support.

Received for publication Sept 19, 2017; accepted for publication Sept 22, 2017; available ahead of print Oct 20, 2017.

Address for reprints: Tom C. Nguyen, MD, Associate Professor of Cardiothoracic Surgery, Director of Minimally Invasive Valve Surgery, University of Texas, 6400 Fannin St, Suite 2850, Houston, TX 77030 (E-mail: tom.c. nguyen@gmail.com).

J Thorac Cardiovasc Surg 2018;155:830-1

$0022-5223 / \$ 36.00$

Copyright (c) 2017 by The American Association for Thoracic Surgery

https://doi.org/10.1016/j.jtcvs.2017.09.105
}

The article in this issue of the Journal by Moffat-Bruce and colleagues $^{1}$ explores an important yet inadequately discussed topic of projected cardiothoracic surgeon supply and demand. From data from the American Board of Thoracic Surgeons, the Society of Thoracic Surgeons, and the Census Bureau, Moffat-Bruce and colleagues ${ }^{1}$ project an inadequate supply of and increased demand for cardiothoracic surgeons by 2035 .

Moffat-Bruce and colleagues ${ }^{1}$ calculated the expected cardiothoracic caseload and obtained projected populations for 2035. They concluded that, from 2010 to 2035, cardiothoracic caseload will increase by approximately $61 \%$, and cases per surgeon will increase by approximately $121 \%$. They are to be congratulated for addressing this important and timely topic with appropriate data analysis and methodology. The article provides a "crystal ball" of sorts, visualizing the future if we do not make changes.

There are several limitations of the article worth mentioning. The conclusions are derived from estimates and assumptions, without substantiated data. Further validation of the estimates would lend more credibility to the results. In addition, Moffat-Bruce and colleagues ${ }^{1}$ do not fully consider emerging and competing technologies such as transcatheter aortic valve replacement, MitraClip, endobronchial ultrasound, stereotactic lung biopsy, and immunotherapy. For example, with respect to aortic stenosis, the advent of transcatheter aortic valve replacement has decreased the number of standard aortic valve replacements performed. ${ }^{2}$ It would also be helpful to provide more granularity regarding the types of cases with the anticipated shortage: coronary revascularization, valvular heart disease, esophageal, or lung surgery, to name a few. This would direct the selection of leaders to address the issue.

This article concurs with several publications regarding future shortage of cardiothoracic surgeons. ${ }^{3-5}$ Despite these predictions, American Board of Thoracic Surgeons certifications continue to decrease, from a high of 168 in

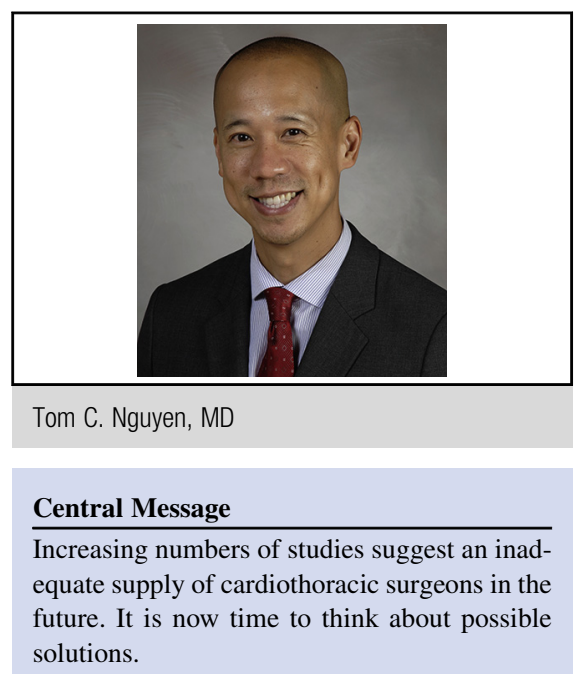

See Article page 824

1998 to 90 in 2014, resulting in fewer qualified surgeons entering the workforce each year, so that increased demand for cardiothoracic surgeons is being met with a decreased supply. ${ }^{6}$

As surgeons, we need to find solutions. Unfortunately, Moffat-Bruce and colleagues ${ }^{1}$ do not provide many. We must attract more residents to the program and be proactive about recruiting talented medical students. This requires much time, energy, and dedication to mentorship. Furthermore, we must focus on graduating more qualified residents. Available evidence indicates a decrease in applicants for the specialty of cardiothoracic surgery. In addition, fewer residents are successful in completing the program. ${ }^{6}$ Creation of more effective training programs is imperative. Surgeons need to ensure that every available opportunity for education and training is maximized, and hospital systems must realize that cases may take longer. Importantly, endovascular and minimally invasive skills should be emphasized during training. A change in emphasis from volume-based to value-based care may decrease demand and mitigate the problem. Value-based care requires the establishment of true health care outcomes on the basis of individual patient needs. ${ }^{7}$

If this shortage continues, we may have to resort to granting access to board certification outside of the United States. If we do not find solutions for this problem, the crystal ball will continue to foresee an inevitable crisis. 


\section{References}

1. Moffatt-Bruce S, Crestanello J, Way DP, Williams TE. Providing cardiothoracic services in 2035: signs of trouble ahead. J Thorac Cardiovasc Surg. 2018;155:824-9.

2. Nguyen TC, Terwelp MD, Thourani VH, Zhao Y, Ganim N, Hoffmann C, et al. Clinical trends in surgical, minimally invasive and transcatheter aortic valve replacement. Eur J Cardiothorac Surg. 2017;51:1086-92.

3. Williams TE Jr, Satiani B, Thomas A, Ellison EC. The impending shortage and the estimated cost of training the future surgical workforce. Ann Surg. 2009;250: 590-7.

4. Williams TE Jr, Sun B, Ross P Jr, Thomas AM. A formidable task: population analysis predicts a deficit of 2000 cardiothoracic surgeons by 2030. J Thorac Cardiovasc Surg. 2010;139:835-40; discussion 840-1.

5. Grover A, Gorman K, Dall TM, Jonas R, Lytle B, Shemin R, et al. Shortage of cardiothoracic surgeons is likely by 2020. Circulation. 2009;120:488-94.

6. Moffatt-Bruce SD, Ross P, Williams TE Jr. American Board of Thoracic Surgery examination: fewer graduates, more failures. J Thorac Cardiovasc Surg. 2014; 147:1464-9.

7. Putera I. Redefining health: implication for value-based healthcare reform. Cureus. 2017;9:e1067. 